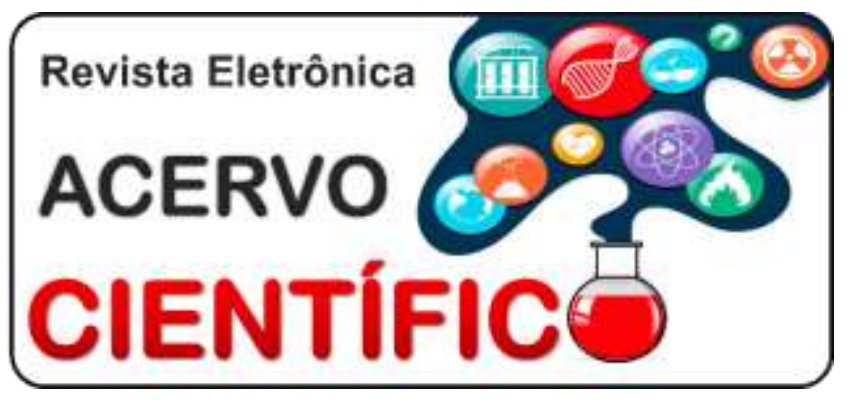

\section{ARTIGO ORIGINAL}

Recebido em: 9/2019

Aceito em: 10/2019

Publicado em: 12/2019

\title{
Avaliação da eficácia antibacteriana do extrato de própolis verde em bactérias causadoras de infecções nas vias aéreas
}

\author{
Evaluation of the antibacterial efficacy of green propolis extract in bacteria causing airway \\ infection
}
Evaluación de la eficacia antibacteriana del extracto de propóleo verde en las bacterias que provocan la infección de las vías aéreas

Henrique Guimarães Vasconcelos ${ }^{1 *}$, Fernanda Odete Souza Rodrigues ${ }^{1}$, Haendel Gonçalves Nogueira Oliveira Busatti².

\begin{abstract}
Resumo: Esse artigo buscou analisar a atividade antibacteriana do extrato de própolis verde sobre as bactérias Staphylococcus aureus e Streptococcus pyogenes, ambas causadoras de infecções nas vias aéreas. As bactérias foram semeadas em placas contendo discos de papel filtro. Para cada espécie foram utilizadas 12 placas, divididas em 3 grupos. No primeiro grupo, os discos de papel foram embebidos em $1 \mathrm{ml}$ de extrato de própolis puro. Já no segundo grupo, os discos foram embebidos em $1 \mathrm{ml}$ de extrato alcoólico de própolis $10 \%$ e, no terceiro grupo, $1 \mathrm{ml}$ de álcool $70 \%$ foi adicionado aos discos. Os halos de inibição foram mensurados e os resultados mostraram maior ação antimicrobiana do extrato em Staphylococcus aureus, mas o crescimento dos Streptococcus pyogenes também foi prejudicado, o que complementa evidências científicas de que o extrato de própolis verde apresenta potencial para uso nas abordagens terapêuticas que envolvem o combate de bactérias patogênicas.
\end{abstract}

Palavras-chave: Própolis, Ação antimicrobiana, Antibacterianos.

\begin{abstract}
This article aimed to analyze the antibacterial activity of green propolis extract on the bacteria Staphylococcus aureus and Streptococcus pyogenes, both causing airway infections. Bacteria were seeded on plates containing filter paper discs. For each species 12 plates were used, divided into 3 groups. In the first group, the paper discs were soaked in $1 \mathrm{ml}$ of pure propolis extract. In the second group, the discs were soaked in $1 \mathrm{ml}$ of $10 \%$ propolis alcohol extract and in the third group, $1 \mathrm{ml}$ of $70 \%$ alcohol was added to the discs. Inhibition halos were measured, and the results showed greater antimicrobial action of the extract in Staphylococcus aureus, but the growth of Streptococcus pyogenes was also impaired, complementing scientific evidence that green propolis extract has potential for use in therapeutic approaches involving the fight against pathogenic bacteria.
\end{abstract}

Keywords: Propolis, Anti-Infective agents, Anti-Bacterial agents.

\footnotetext{
1 Universidade de Itaúna (UIT), Itaúna - MG. *E-mail: guimaraes.henrique@yahoo.com

2 Universidade Federal de Minas Gerais (UFMG), Belo Horizonte - MG
} 
Resumen: Este artículo pretende analizar la actividad antibacteriana del extracto de propóleo verde en las bacterias Staphylococcus aureus y Streptococcus pyogenes, que causan infecciones de las vías respiratorias. Se sembraron bacterias en placas que contenían discos de papel de filtro. Para cada especie se utilizaron 12 placas, divididas en 3 grupos. En el primer grupo, los discos de papel se remojaron en $1 \mathrm{ml}$ de extracto puro de propóleos. En el segundo grupo, los discos se empaparon en $1 \mathrm{ml}$ de extracto de alcohol de propóleo al $10 \%$ y en el tercer grupo, se añadió $1 \mathrm{ml}$ de alcohol al $70 \%$ a los discos. Se midieron los halos de inhibición y los resultados mostraron una mayor acción antimicrobiana del extracto en Staphylococcus aureus, pero el crecimiento de Streptococcus pyogenes también se vio afectado, lo que complementa la evidencia científica de que el extracto de propóleo verde tiene potencial para su uso en enfoques terapéuticos que involucran la lucha contra las bacterias patógenas.

Palabras clave: Própole, Antiinfecciosos, Antibacterianos.

\section{INTRODUÇÃO}

As infecções das vias aéreas superiores (IVAS) constituem o grupo de doenças que mais acometem os seres humanos, sendo a população adulta capaz de desenvolver de 2 a 5 episódios anuais, enquanto crianças apresentam 7 a 10 episódios ao ano. Elas estão entre as causas mais comuns de consulta aos profissionais de saúde e, embora os quadros da doença sejam caracteristicamente leves, as altas taxas de incidência e de transmissão as colocam entre as principais causas de absenteísmo no trabalho e na escola (ZABOT F, 2018; SILVA FILHO EB, et al., 2017).

Apesar de boa parte das infecções respiratórias ter etiologia viral (cerca de $75 \%$ ), para as quais o tratamento com drogas antimicrobianas não traz nenhum benefício, a prescrição de antimicrobianos persiste como prática comum (MONTEIRO AB, et al., 2011). Ainda nos casos em que a infecção é de origem bacteriana e há indicação para o uso de antibióticos, os erros nas fases de prescrição, administração, dispensação e na transcrição dos medicamentos prescritos corroboram para o crescente uso abusivo dessas drogas (MARQUES TC, 2008).

Como consequência do mau uso dos antibióticos, surgem problemas significativos como o encarecimento da terapêutica, o aumento do perfil de efeitos adversos e, de modo ainda mais importante, o fenômeno descrito como "pressão antibiótica". Esse processo se refere à relação entre a extensão do uso desses medicamentos e a seleção de cepas resistentes e constitui uma alarmante ameaça para a saúde pública em todo o mundo (SPURLING GKP, et al., 2013).

Frente aos potenciais desafios desencadeados pelo uso dos antimicrobianos convencionais, têm sido crescentes os estudos que visam analisar a eficácia terapêutica de substâncias naturais com o objetivo de consolidá-las como alternativa à terapia medicamentosa habitual. Nesse contexto, em especial, a própolis desponta como opção acessível e benéfica para o tratamento de infecções das vias aéreas superiores causadas por bactérias (YUSKEL S e AKYOL S, 2016).

A própolis, cujo nome é derivado do grego e significa "em defesa da comunidade", é utilizada sob a forma de extrato na medicina popular desde 300 a.C. em razão de suas importantes propriedades farmacológicas. Sua composição química é diversificada, incluindo flavonoides (como a galangina, quercetina, pinocembrina e kaempferol), ácidos aromáticos e ésteres, aldeídos e cetonas, terpenoides e fenilpropanoides (como os ácidos caféico e clorogênico), esteroides, aminoácidos, polissacarídeos, hidrocarbonetos, ácidos graxos e vários outros compostos em pequenas quantidades. Elementos inorgânicos tais como cobre, manganês, ferro, cálcio, alumínio, vanádio e silício também são componentes dessa substância, não se ignorando que há variação importante na constituição da própolis de acordo com a flora da região e época da colheita, com a técnica empregada e a espécie da abelha produtora (LUSTOSA SR, et al., 2008).

Entre as classes de compostos supracitadas, destacam-se os flavonoides e os ácidos fenólicos, cuja importância reside em seu potencial antibacteriano, antiviral e antioxidante (FERNANDES JA, et al., 2001). Diante dos resultados obtidos em estudos anteriores, tal potencial possivelmente se deve ao fato de esses 
compostos atuarem sobre a inibição da RNA-polimerase bacteriana ou sobre a membrana e/ou parede celular do microrganismo, causando danos funcionais e estruturais, assim como muitos dos antibióticos convencionais (MAGALHÃES TV, et al., 2016).

Apesar de ser notório o acervo nacional e internacional sobre as propriedades medicinais da própolis e de ela ser aceita por órgãos regulatórios como produto com finalidade terapêutica, ainda se faz necessária a determinação de parâmetros que devem ser mensurados para comprovar a atividade farmacológica da própolis comercial. Também são necessárias pesquisas que estabeleçam a relação entre composição química e atividade biológica, o que permitirá correlacionar o tipo de própolis com a sua aplicação na área da saúde. Uma vez que diversos fatores podem interferir na composição química, a obtenção de tais parâmetros e correlações representa real desafio (PEREIRA AS, et al., 2002).

Diante de todo o cenário apresentado, a presente pesquisa objetivou endossar os trabalhos científicos publicados até o momento atual e fomentar a elaboração de novos estudos. A partir de métodos e processos bem delineados e pré-determinados, foi avaliada a eficácia de diferentes concentrações de extrato de própolis verde sobre bactérias das espécies Staphylococcus aureus e Streptococcus pyogenes, ambas causadoras de infecções das vias aéreas superiores, e quantificada sua capacidade de inibir o crescimento microbiano.

\section{MÉTODOS}

Trata-se de uma pesquisa experimental em que o objeto de estudo foi o extrato de própolis verde adquirido em farmácias especializadas em manipulação. As amostras bacterianas de Staphylococcus aureus e Streptococcus pyogenes foram fornecidas por um laboratório de um munícipio do estado de Minas Gerais e a pesquisa foi realizada no laboratório de Microbiologia do curso de Medicina da Universidade de Itaúna.

Para a realização da pesquisa, utilizaram-se placas de petri contendo meio de cultura ágar Mueller Hinton, discos de papel filtro estéreis de $1 \mathrm{~cm}$ de diâmetro, pipetas automáticas, alças de platina e estufa de cultura bacteriológica, além do extrato de própolis verde puro, extrato alcoólico de própolis verde $10 \%$ e do álcool $70 \%$.

A análise estatística foi realizada pelo cálculo das médias e desvios padrões dos valores referentes aos diâmetros dos halos de inibição encontrados nas placas de petri através do software Microsoft Excel®.

\section{RESULTADOS}

Inicialmente, as amostras bacterianas de Staphylococcus aureus e Streptococcus pyogenes recebidas foram cultivadas em placas de petri contendo ágar Mueller Hinton para a obtenção de colônias. Em seguida, as mesmas foram cultivadas em caldo Tioglicolato por 24 horas e, posteriormente, semeadas em placas de petri contendo ágar Mueller Hinton e 5 discos de papel filtro de $1 \mathrm{~cm}$ de diâmetro.

Para cada espécie de bactéria foram utilizadas 12 placas, sendo estas divididas em 3 grupos de 4 placas. No primeiro grupo, os discos de papel filtro estéreis foram embebidos em $1 \mathrm{ml}$ de extrato de própolis verde puro. Já no segundo grupo, os discos foram embebidos em $1 \mathrm{ml}$ de extrato alcoólico de própolis verde $10 \%$ e, no terceiro grupo, $1 \mathrm{ml}$ de álcool $70 \%$ foi adicionado aos discos. Para garantir que a exata quantidade das substâncias fosse adicionada aos discos foram utilizadas pipetas automáticas.

Após esse processo, as placas foram colocadas em uma estufa por 48 horas. Em seguida, os halos de inibição formados nas placas foram mensurados em milímetros com a utilização de régua adequada a tal finalidade e registrados em tabelas (Tabelas 1 e 2). Para que os resultados fossem analisados, foram calculados as médias e os desvios padrões dos halos de inibição observados em cada uma das 12 placas e, ainda, foi calculada a média de todos os halos pertencentes ao mesmo grupo de placas $\left(1^{\circ}, 2^{\circ}\right.$ e $3^{\circ}$ grupo).

Em relação aos testes com Streptococcus pyogenes (Tabela 1), observou-se que os halos de inibição apresentaram uma média de $4,25 \mathrm{~mm}$ de raio quando o extrato puro de própolis verde foi adicionado aos discos de papel filtro. Quanto ao uso do extrato alcoólico de própolis verde $10 \%$ e do álcool $70 \%$, as médias encontradas foram, respectivamente, $1,15 \mathrm{~mm}$ e $0,35 \mathrm{~mm}$ de raio. 
Tabela 1 - Tamanho médio dos raios dos halos de inibição em milímetros.

\begin{tabular}{cccc}
\hline \multicolumn{3}{c}{ Staphylococcus aureus } \\
\hline Placas & Extrato puro de própolis verde & Extrato alcoólico de própolis verde $\mathbf{1 0 \%}$ & Álcool 70\% \\
\hline 1 & 6,2 & 3,4 & 0,7 \\
2 & 5,2 & 4,2 & 0,9 \\
3 & 6 & 3,2 & 0,9 \\
4 & 5,4 & 3 & 0,7 \\
\hline $\begin{array}{l}\text { Média } \mathbf{E} \text { Desvio } \\
\text { Padrão }\end{array}$ & $\mathbf{5 , 7} \pm \mathbf{0 , 4 1}$ & $\mathbf{3 , 4 5} \pm \mathbf{0 , 4 5}$ & $\mathbf{0 , 8} \pm \mathbf{0 , 1}$ \\
\hline
\end{tabular}

Fonte: Vasconcelos HG, Rodrigues FOS, Busatti HGNO, 2019.

Nos testes realizados com Staphylococcus aureus (Tabela 2), obteve-se uma média de 5,7 $\mathrm{mm}$ de raio quando utilizado o extrato puro, 3,45 mm com o uso do extrato de própolis verde $10 \%$ e 0,8 mm ao se adicionar álcool $70 \%$ nos discos.

Tabela 2 - Tamanho médio dos raios dos halos de inibição em milímetros

\begin{tabular}{|c|c|c|c|}
\hline \multicolumn{4}{|c|}{ Staphylococcus aureus } \\
\hline Placas & Extrato puro de própolis verde & Extrato alcoólico de própolis verde $10 \%$ & Álcool 70\% \\
\hline 1 & 6,2 & 3,4 & 0,7 \\
\hline 2 & 5,2 & 4,2 & 0,9 \\
\hline 3 & 6 & 3,2 & 0,9 \\
\hline 4 & 5,4 & 3 & 0,7 \\
\hline $\begin{array}{l}\text { Média } \pm \\
\text { Padrão }\end{array}$ & $5,7 \pm 0,41$ & $3,45 \pm 0,45$ & $0,8 \pm 0,1$ \\
\hline
\end{tabular}

Fonte: Vasconcelos HG, Rodrigues FOS, Busatti HGNO, 2019.

Com base nestes resultados, as propriedades antimicrobianas do extrato de própolis se mostraram mais intensas nos testes com Staphylococcus aureus, nos quais a média dos halos obtidos a partir do extrato puro $(5,7 \mathrm{~mm})$ foi aproximadamente $1,65 \mathrm{vez}$ maior quando comparada à média obtida com o uso do extrato alcoólico de própolis verde $10 \%$ (3,45 mm) e 7,13 vezes maior em relação ao valor encontrado com o uso do álcool 70\% (0,8 mm).

No entanto, os extratos de própolis verde também demonstraram considerável atividade antimicrobiana nos ensaios com Streptococcus pyogenes. Nestes testes, a média dos halos obtidos a partir do extrato puro $(4,25 \mathrm{~mm})$ foi aproximadamente 3,69 vezes maior quando comparada à média obtida com o uso do extrato alcoólico de própolis verde $10 \%(1,15 \mathrm{~mm})$ e 12,14 vezes maior em relação ao valor encontrado com o uso do álcool 70\% (0,35 mm) (Gráfico 1). 
Gráfico 1 - Tamanho médio dos raios dos halos de inibição em milímetros

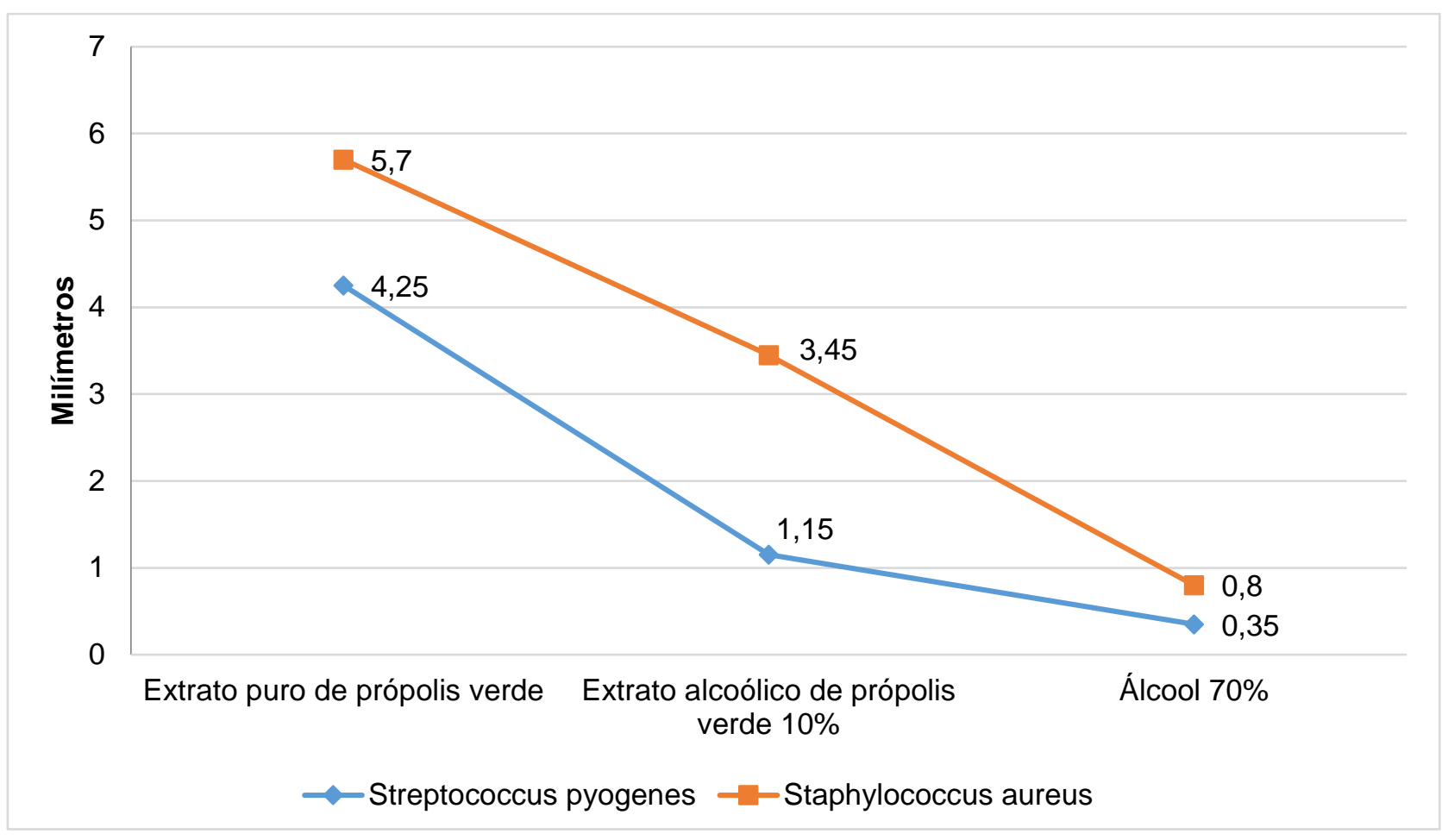

Fonte: Vasconcelos HG, Rodrigues FOS, Busatti HGNO, 2019.

\section{DISCUSSÃO}

Crescentes pesquisas sobre as propriedades da própolis mostraram que seu extrato cessa o crescimento bacteriano por inibir a divisão celular e por produzir defeitos na estrutura da parede celular, levando à bacteriólise parcial e desorganizando o citoplasma, que passa a apresentar espaços vazios ou estruturas fibrosas. Ainda, o extrato de própolis pode agir alterando a membrana citoplasmática bacteriana e inibindo a síntese proteica. Uma vez que esses mecanismos se assemelham àqueles apresentados pelos antibióticos convencionais, surge a possibilidade de concretizar o uso dessa substância natural para fins farmacológicos (LOPEZ BG, et al., 2015).

Muitos estudos sugerem que a associação de extratos de própolis com antimicrobianos viabilize diminuir a dosagem clínica de certos antibióticos e, dessa forma, minimizar a ocorrência de efeitos colaterais e intensificar a antibioticoterapia no tratamento de infecções cuja resistência bacteriana esteja presente (RIPARI N, et al., 2019).

Dentre tais estudos, muitos têm identificado maior atividade da própolis em relação aos vários antibióticos testados e, além disso, relatam a atividade sinérgica da própolis associada a diversos antibióticos, inclusive contra cepas resistentes a Benzilpenicilina, Tetraciclina, Eritromicina, Cloranfenicol, Gentamicina, Netilmicina, Vancomicina e Clindamicina (SFORCIN JM, 2009; RIPARI N, et al., 2019).

Trabalhos científicos realizados até o presente momento apresentaram resultados semelhantes ao desta pesquisa. O estudo de Magalhães TV, et al. (2016) demonstrou que a utilização dos discos de papel filtro com álcool livre de extrato de própolis verde apresentou menor efeito antimicrobiano nos agentes avaliados em comparação com os resultados encontrados ao se utilizar discos com extrato puro e extrato alcoólico $10 \%$.

Com relação ao uso do extrato de própolis verde, a pesquisa realizada por Bosio K, et al. (2000) também manifestou ação antibacteriana em amostras de Streptococcus pyogenes, sendo esta ação diretamente proporcional à concentração e à quantidade do extrato de própolis utilizado. 
Estudo de Pinto MS, et al. (2001) encontrou raios de halos de inibição do crescimento do Staphylococcus aureus com tamanhos variando entre 4,33 e 5,58 mm. Essas dimensões se assemelham àquelas encontradas pela pesquisa relatada neste presente artigo.

Brumfitt W, et al. (1990), em experimento semelhante, encontraram halos de inibição do crescimento de Staphylococcus aureus com raios que variaram entre 3,5 e $7 \mathrm{~mm}$ ao se utilizar discos de papel de filtro com $6 \mathrm{~mm}$ de diâmetro impregnados com extrato alcoólico própolis na mesma concentração utilizada neste trabalho, ou seja, 10\%. Esta mesma concentração foi utilizada por Bankova V, et al. (1998) que, trabalhando com amostras de própolis brasileira, encontraram halos de inibição cujos raios variaram entre 3 e $5 \mathrm{~mm}$.

Kujumgiev A, et al. (1999), estudando estas mesmas amostras brasileiras, observaram halos variando entre 5 e 6,5 mm de diâmetro. Ademais, a pesquisa realizada com própolis da Polônia por Dobrowolski JW, et al. (1991) encontrou raio médio de $8 \mathrm{~mm}$ usando uma concentração de $300 \mathrm{mg} / \mathrm{ml}$ de extrato alcoólico de própolis, que também se assemelha aos valores encontrados pelos demais pesquisadores.

Contudo, ainda que os resultados se assemelhem, é importante destacar que os métodos utilizados para a avaliação da inibição da proliferação bacteriana podem modificar significativamente os valores encontrados por cada pesquisador. Além disso, aspectos associados à técnica de extração da própolis, local de origem e época do ano em que foi produzida podem ter influência sobre o maior ou menor grau de inibição da substância em relação às diferentes espécies bacterianas (DALEPRANE JB e ABDALLA DS, 2013).

\section{CONCLUSÃO}

Tanto as bactérias da espécie Streptococcus pyogenes quanto as bactérias da espécie Staphylococcus aureus mostraram-se sensíveis aos extratos de própolis verde utilizados, sendo o extrato puro aquele que demonstrou maior atividade antimicrobiana em ambas as espécies. Assim, existe a possibilidade de sua indicação médica com a finalidade de tratar infecções nas vias aéreas superiores se tornar frequente na prática clínica caso mais estudos sejam realizados. Além disso, os resultados desta pesquisa reforçam e complementam as evidências científicas de que a própolis apresenta significativos benefícios à saúde humana e que possui potencial para assumir papel de destaque nas abordagens terapêuticas que envolvem o combate de bactérias patogênicas.

\section{SIGLAS E ABREVIAÇÕES}

\%: por cento, a.C.: antes de Cristo, RNA: ácido ribonucleico, $\mathbf{m m}$ : milímetros, $\mathbf{c m}$ : centímetros, ml: mililitro.

\section{REFERÊNCIAS}

1. BANKOVA V, et al. Seasonal variations of the chemical composition of Brazilian propolis. Apidologie. 1998; 29: 361 367.

2. BOSIO K, et al. In vitro activity of propolis against Streptococcus pyogenes. Letters in Applied Microbiology. 2000; 31 : 174-177.

3. BRUMFITT W, et al. Antibiotic activity of natural products: 1. Propolis. Microbios. 1990; 62: 19-22.

4. DALEPRANE JB, ABDALLA DS. Emerging roles of propolis: antioxidant, cardioprotective and antiangiogenic actions. Evidence-based Complementary and Alternative Medicine. 2013; 2013:175135.

5. DOBROWOLSKI JW, et al. Antibacterial, antifungal, antiamoebic, antiinflammatory and antipyretic studies on propolis bee products. Journal of Ethnopharmacology. 1991; 35: 77-82.

6. FERNANDES JA, et al. The antibacterial activity of propolis produced by Apis mellifera $\mathrm{L}$. and Brazilian stingless bees. J Venom. Anim. Toxins. 2001; 7(2): 173-182.

7. KUJUMGIEV A, et al. Antibacterial, antifungal and antiviral activity of propolis of different geographic origin. Journal of Ethnopharmacology. 1999; 64: 235-240.

8. LOPEZ BG, et al. Antimicrobial and cytotoxic activity of red propolis: an alert for its safe use. Journal of Applied Microbiology. 2015; 119: 677-687. 
9. LUSTOSA SR, et al. Própolis: atualizações sobre a química e a farmacologia. Rev. Bras. Farmacogn. 2008; 18(3): 447-454.

10. MAGALHÃES TV, et al. Analise da ação antibacteriana da própolis e padronização de volumes através de antibiograma. UNIMAR CIÊNCIAS. 2016; 25(1-2): 38-44.

11. MARQUES TC, et al. Erros de administração de antimicrobianos identificados em estudo multicêntrico brasileiro. Revista Brasileira de Ciências Farmacêuticas. 2008; 44(2): 305-314.

12. MONTEIRO AB, et al. Perfil de prescrição antibiótica no tratamento das Infecções das Vias Aéreas Superiores. Ver. Port. Clin. Geral. 2011; 27(6): 502-506.

13. PEREIRA AS, et al. Própolis: 100 anos de pesquisa e suas perspectivas futuras. Quim. Nova. 2002; 25(2): 321 -326.

14. PILTCHER OB, et al. Como evitar o uso inadequado de antibióticos nas infecções de vias aéreas superiores? Posição de um painel de especialistas. Braz. J. Otorhinolaryngol. 2018; 84(3): 265-279.

15. PINTO MS, et al. Efeito de extratos de própolis verde sobre bactérias patogênicas isoladas do leite de vacas com mastite. Braz J Vet Res Anim Sci. 2001; 38(6): 278-283.

16. SFORCIN JM. Própolis e imunidade: comprovações científicas. São Paulo. Editora UNESP. 2009; 67p.

17. SILVA FILHO EB, et al. Infecções Respiratórias de Importância Clínica: uma Revisão Sistemática. Revista Fimca. 2017; 4(1): 7-16

18. SPURLING GKP, et al. Delayed antibiotics for respiratory infections. Cochrane Database of Systematic Reviews. 2013; 4: CD004417.

19. YUSKEL S, AKYOL S. The consumption of propolis and royal jelly in preventing upper respiratory tract infections and as dietary supplementation in children. J Intercult. Ethnopharmacol. 2016; 5(3): 308-311.

20. ZABOT F. Revisão bibliográfica: infecção de vias aéreas superiores (IVAS). Revista Uniplac. 2018; 6(1): $209-215$. 